\title{
Greening France
}

Last update: 14 March 2017

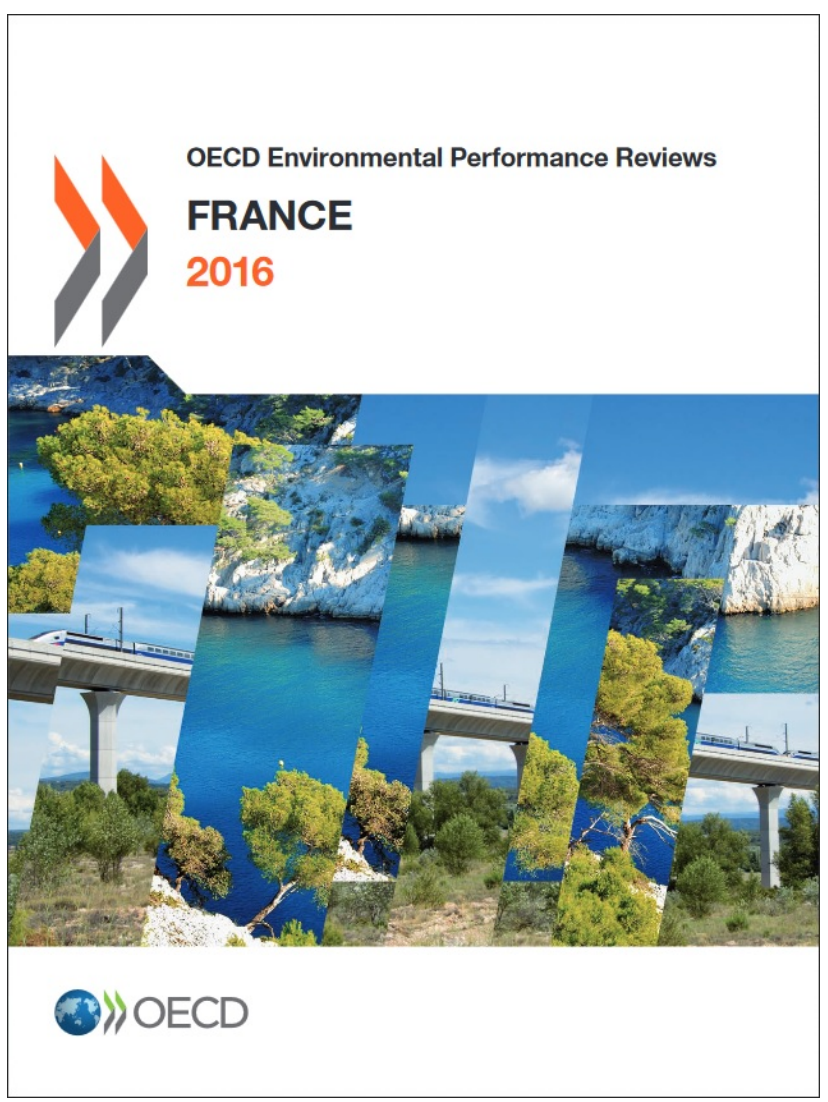

France has significantly improved its environmental performance over the past ten years, as evidenced by the signing of the Paris Agreement and the entry into force of the Energy Transition for Green Growth Act, both of which promote the protection of biodiversity, responsible management of resources and the fight against waste, and sketch out a new model of participative governance. But there remain gaps in the country's environmental policy, according to the latest Environmental Performance Review of France, which advises the French government to waste no time in implementing its energy transition.

The OECD's Environmental Performance Reviews assess the progress made by the organisation's member countries and its partners in terms of environmental governance. The review of France singles out specific fields where significant, concrete progress has been made, including the reduction of greenhouse gas 
emissions and the main atmospheric pollutants, the inclusion of a carbon factor in the taxation of fossil fuels and the adoption of a plan to fight against air pollution in the city of Paris (see references). This plan advocates the involvement of the public by offering subsidies for the acquisition of electric bikes and vehicles, expanding cycle lanes and incentivising the use of public transport.

The review identifies the challenges facing France: first, restricting land-take, and taking action against the pollution of groundwater with nitrates and pesticides, since France is one of the world's biggest consumers of plant protection products. Second, improving air quality, particularly at a time when over two million people living in the greater Paris area are exposed to levels of fine particulates that exceed regulatory limits and have damaging effects on both the environment and human health. The country also needs to increase the protection of land and marine ecosystems, which form part of the country's extraordinary biodiversity.

The multi-layered institutional mosaic of France's regional administrationknown by the French as a millefeuille after a layered pastry-hampers many initiatives, and some of the plans that have been introduced are not restrictive enough or are based on loosely defined forms of governance. The OECD review stresses that the recent reforms to the country's regional organisation is a step in the right direction.

See www.oecdobserver.org/books

\section{References}

OECD Environmental Performance Reviews: France 2016 http://dx.doi.org/ 10.1787/9789264252714-en 